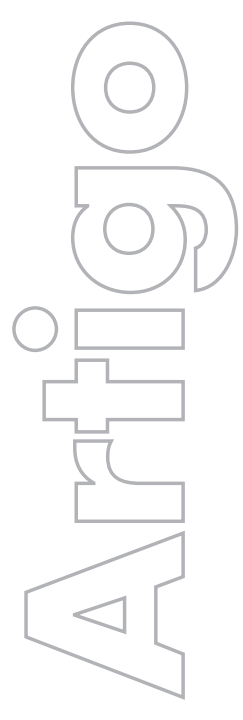

revista

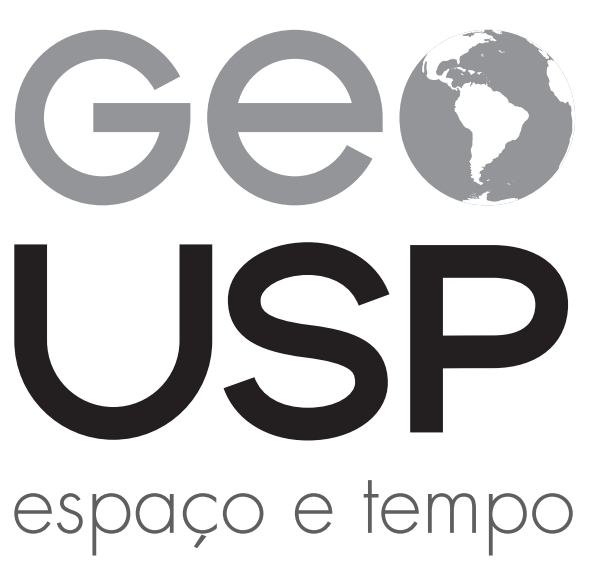

Volume $20 \cdot n^{\circ} 1(2016)$
O professor de geografia do ensino superior e a docência: um campo de múltiplos saberes e racionalidades

Francisco Kennedy Silva dos Santos

UFPE

p. $142-159$

Como citar:

SANTOS, F. K. S. O professor de geografia do ensino superior e a docência: um campo de múltiplos saberes e racionalidades. Geousp - Espaço e Tempo (Online), v. 20, n. 1, p. 142-159, mês. 2016. ISSN 2179-0892.

Disponível em: http://www.revistas.usp.br/geousp/article/ view/100714. DOI: http://dx.doi.org/10.11606/issn.21790892.geousp.2016.100714.

\section{(c) $(1) \otimes$}

Este artigo está licenciado sob a Creative Commons Attribution 4.0 License. 


\title{
O professor de geografia do ensino superior e a docência: um campo de múltiplos saberes e racionalidades
}

\section{Resumo}

Este artigo é resultado de uma investigação sobre os limites e as possibilidades da racionalidade pedagógica no ensino superior, na docência do professor universitário. A fundamentação teórica ancora-se em diversos estudos que procuram mapear as racionalidades que movem esses profissionais em situação de trabalho, tendo como referencial a epistemologia da prática e a pedagogia universitária. Diante da complexidade do objeto, usou-se da pesquisa qualitativa, porque privilegia os significados dos sujeitos da pesquisa. Os resultados mostram que, movidos por uma racionalidade técnica, os docentes investigados têm uma pedagogia própria, pautada na transmissão do conteúdo.

Palavras-chave: Educação Superior. Trabalho docente. Racionalidade pedagógica. Formação docente. Mediação pedagógica.

\section{The geography teacher of higher education and teaching: a multiple field of knowledge and rationalities}

\begin{abstract}
This article is the result of an investigation whose purpose work and teaching in higher education, the role of university professor, with the central focus on the limits and possibilities of the pedagogical rationale in higher education. The theoretical foundation anchors in several studies that seek to map the rationales that drive these professionals work situation, taking as reference the epistemology of practice and university pedagogical. Given the complexity of the object, we used qualitative research, since this emphasizes the significance of the research subjects. The survey results show that the teachers investigated, moved by a technical rationality, have their own pedagogy guided in the transmission of content.
\end{abstract}

Keywords: Higher Education. Teaching work. Pedagogical rationality. Teacher training. Pedagogical mediation. 


\section{Primeira aproximação}

Ensinar é uma tarefa complexa na medida em que exige um conhecimento consistente da disciplina ou de suas atividades, da maneira como os estudantes aprendem e de como serão conduzidos os recursos de ensino a fim de que se ajustem melhor às condições do trabalho que será feito (Zabalza, 2004).

Conhecer bem a própria disciplina é uma condição fundamental, mas não é o suficiente. A capacidade intelectual do docente e a forma como abordará os conteúdos são muitos distintas de como o especialista o faz. Esta é uma maneira de se aproximar dos conteúdos ou das atividades profissionais pensando em estratégias para fazer com que os alunos aprendam.

Nas últimas décadas, o corpo docente universitário se constitui, em grande parte, por profissionais renomados, com sucesso em suas atividades profissionais, tendo como base a profissão paralela que exercem ou exerciam no mundo do trabalho, acreditando que quem sabe, automaticamente, sabe ensinar. Esses profissionais, ao chegarem à universidade, trazem consigo inúmeras experiências do que é ser professor. Experiências estas adquiridas como alunos durante sua vida escolar, que lhe permitirão construir modelos que utilizarão por toda a sua carreira docente (Pimenta; Anastasiou, 2002).

Ainda segundo as autoras, o desafio nos dias atuais é o de construir a identidade do docente universitário, para aqueles profissionais que têm os saberes da experiência, mas não se identificam como professores.

Sobre o rito de passagem de aluno a professor universitário, Tardif, Lessard e Lahaye (1991) consideram que, no exercício cotidiano de sua função, o professor defronta-se com vários limites concretos que não são previsíveis e passíveis de uma definição acabada. $\bigcirc$ docente desenvolve, então, habilidades pessoais, tais como capacidade de improvisação, "macetes", gestos, atitudes e estilos que possibilitem vencer as barreiras e construir um modo próprio de ensinar.

Para Masetto (2002), a universidade e os professores universitários começam a se conscientizar que a docência, como o exercício de qualquer profissão, exige capacitação própria e específica, não se restringindo a um diploma de bacharel, mestre ou doutor, ou ainda, ao exercício de uma profissão. Exige tudo isso, além de outras competências próprias.

Em sua pesquisa sobre o professor universitário, Behrens (2003, p. 57-59) constatou que o magistério nas universidades tem sido exercido por profissionais das mais diversas áreas do conhecimento e identificou quatro grupos de professores e professoras, os quais, à primeira vista, parece ser característica do corpo docente de quase todas as universidades: (a) profissionais de diferentes áreas que se dedicam à docência em tempo integral, (b) profissionais liberais que atuam na área específica do curso que lecionam, (c) profissionais da área de educação que atuam em cursos de pedagogia e/ou licenciaturas na universidade e também na educação infantil, no ensino fundamental ou médio, e (d) profissionais da área de educação e de licenciaturas em tempo integral na educação superior.

Behrens (2003, p. 60) segue atribuindo a essa classificação duas denominações: professor-profissional e profissional-professor. Explicita que essa diversidade é muito importante na composição do quadro docente, mas ressente que grande parte desse contingente não tenha formação pedagógica. Se considerarmos que grande parte dos professores pesquisados que tem formação pedagógica obteve qualificação docente pela formação acadêmica, talvez a expectativa se torne mais frustrante. 
Diante desse quadro, em sua prática cotidiana, o professor se depara com situações rotineiras, que exigem o uso de um repertório construído ao longo do tempo, repertório esse baseado em suas experiências e na sua formação e que, ao mesmo tempo lhe abre inúmeras oportunidades quando se vê diante de situações nunca vividas e, para as quais precisa colocar em funcionamento recursos cognitivos e emocionais pouco ou nunca testados.

É nesse cenário de incertezas que os docentes universitários são movidos por uma racionalidade instrumental alimentada pela experiência herdada de seus antigos mestres. Entretanto, diversos estudos procuram mapear as racionalidades que movem esses profissionais em situação de trabalho (Tardif; Lessard; Lahaye, 1991; Therrien, 1996, 1997, 2006; Moreira; Lopes; Macedo, 1998; Tardif, 1999, 2002; Pimenta, 2006; Sacristán, 1996, 1999; Zabalza, 2000, 2004; Zeichner, 2000, entre outros).

Como objetivo geral da pesquisa aqui anunciada, procuramos compreender os elementos constituintes da relação teoria-prática no trabalho docente desenvolvido no curso de geografia de duas instituições públicas de ensino superior e dos saberes e suas implicações resultantes para o processo de formação contínua do professor reflexivo-crítico.

\section{Caminhos trilhados e trilhas que se entrelaçam}

Diante da complexidade do objeto, optamos pela pesquisa qualitativa considerada o caminho mais indicado a trilhar, uma vez que esta privilegia os significados, experiências, motivos, sentimentos, atitudes e valores dos professores envolvidos com o fenômeno a ser investigado: a docência na educação superior na perspectiva de professores formados em áreas não pedagógicas. Esse modelo de pesquisa condiz mais com o tipo de problema deste estudo, uma vez que "[...] ela aborda o conjunto de expressões humanas constantes nas estruturas, nos processos, nos sujeitos, nos significados e nas representações" (Minayo, 1994, p. 15). Aproximamo-nos, portanto da etnometodologia e da ergonomia do trabalho docente.

Etnometodológica porque o objeto de estudo impõe a realização de uma pesquisa de campo, em que os dados serão coletados in loco, não para serem testados, mas sim interpretados e conceitualizados. Além disso, a etnometodologia, segundo Coulon (1995), permite compreender como os membros de um grupo dão significados a suas práticas em um contexto específico. Caracteriza-se por estudar os etnométodos que os atores utilizam no seu dia a dia que lhes permitem viverem juntos, inclusive de maneira conflitiva, e que regem as relações sociais que eles mantêm entre si.

A opção pelo uso da ergonomia do trabalho docente se dá em função da necessidade de melhor compreender o trabalho concreto dos professores como profissionais críticos-reflexivos, a fim de se construir um entendimento da dinâmica da docência (Therrien, 1997).

A temática escolhida não é algo que possa ser quantificado, pois segundo Dias (2010, p. 81-82), incorpora significados e motivos que não podem ser "[...] reduzidos à operacionalização de variáveis" (Minayo, 1994, p. 18). Assim, utilizaram-se dos seguintes procedimentos: a revisão bibliográfica; aplicação de questionários com questões abertas e fechadas; realização de entrevistas; e a observação não participante.

Para seleção dos professores que participaram como sujeitos da pesquisa, tomamos inicialmente os seguintes critérios, tendo como intencionalidade investigarmos somente professores bacharéis sem formação pedagógica que contribuíssem para elucidar nosso problema 
de pesquisa: tiveram a formação inicial em curso de bacharelado em geografia; fizeram pós-graduação stricto sensu na área dos cursos investigados; não cursaram a disciplina de Didática do Ensino Superior ou Metodologia do Ensino Superior durante a pós-graduação; atuam na educação superior como docentes no mínimo 5 anos.

Definidos os critérios, foram distribuídos 32 questionários - "Questionário de identificação dos sujeitos da pesquisa", com o objetivo de conhecer os docentes de cada instituição de ensino superior e quais atendiam aos critérios anteriormente mencionados.

Dos 32 questionários distribuídos, obtivemos a resposta de 20, entre os quais somente 12 atendiam aos critérios estabelecidos para a escolha dos sujeitos, sendo oito pertencentes ao quadro permanente da Universidade Federal de Pernambuco (UFPE) e quatro do da Universidade Estadual do Ceará (UECE). Posteriormente, fizemos contato via e-mail com os outros 12 professores para saber os motivos do não preenchimento e devolutiva do questionário. Dos 12, obtivemos retorno de 6, que alegaram falta de tempo.

$\bigcirc$ consentimento em participar da pesquisa foi a maior barreira. Parecia-nos que alguns professores se colocavam em uma atitude defensiva, por se tratar de uma pesquisa que envolvia sua prática com ênfase na formação e na mobilização de saberes. Lembramo-nos que ao apresentar a proposta aos professores, ouvimos, frases como "vai nos ensinar a dar 'aula' aceito, mas não vai rir de mim".

As entrevistas, consideradas um importante instrumento de coleta de dados, foram realizadas no segundo momento da pesquisa. Optamos pela entrevista individual semiestruturada, com a utilização de um roteiro pré-estruturado do qual constavam questões fundamentais aos objetivos do estudo e que auxiliariam para não perder o foco desejado. $\bigcirc$ roteiro pré-estruturado de entrevista privilegiou informações referentes: ao ingresso no magistério superior; à atuação profissional - aspectos ligados ao planejamento das aulas e à formação para a docência; à participação do professor em atividades de aperfeiçoamento profissional, com destaque à formação pedagógica; e ao contexto da universidade.

Com o objetivo da investigação direta da prática do professor, optamos pela observação dos sujeitos em situação de aula, que constitui uma das etapas da pesquisa de campo e implica no acompanhamento de todas as etapas do trabalho docente, que inclui o planejamento e a execução das aulas ministradas pelos professores selecionados, conforme critérios anteriormente citados.

Para análise e tratamento dos dados, optou-se pela análise de conteúdos, como proposto por Bardin (1995). A partir da orientação desse autor, na fase de organização dos dados, fizemos a transcrição integral do material coletado, com o objetivo de se resgatar todo o conteúdo temático gerado.

Na transcrição dos dados do questionário e posteriormente das demais etapas da pesquisa - entrevistas semiestruturadas e observação não participante de aula - utilizou-se uma sigla contendo dados de identificação dos docentes com o intuito de garantir o anonimato. Cada sujeito recebeu a identificação: G - geografia, seguido de um algarismo (por exemplo, Gl).

Uma vez concluída cada fase da pesquisa, os dados obtidos foram tabulados, usando-se o software NVivo. Agrupamos as falas dos sujeitos referentes a um mesmo assunto ora intitulando cada conjunto com palavras-chave decorrentes dos próprios "discursos", ora con- 
servando o discurso sobre determinada temática. Os temas foram interpretados, buscando estabelecer relações com o referencial teórico que norteou este trabalho. Através dessa metodologia buscamos identificar a significação dos dados coletados resultantes das entrevistas, questionários e das observações.

\section{A epistemologia da prática profissional como constructo para a prática docente no ensino superior}

Iniciamos nossa reflexão nessa seção, assumindo a postura de pesquisador/professor para além da prática - ou seja, para um campo de reflexividade apoiado em Therrien (2006), concebido como espaço para a transformação pedagógica da matéria. "A transformação pedagógica da matéria ocorre a partir das interações com os alunos. É um saber situado construído pela racionalidade pedagógica na busca de entendimento intersubjetivo". (Therrien, 2006, p. 18).

Nesse contexto, a prática docente, que produz saberes, precisa ser epistemologicamente assumida, e isso se faz pelo seu exercício como práxis, permeada por sustentação teórica, que fundamenta o exercício crítico-reflexivo dos professores. Nela, sujeito e realidade dialogam, se transformam e são por ela transformados.

Os saberes requerem a presença do sujeito intermediando a teoria com as condições da prática; para tanto saberes não existem dissociados do sujeito, mas amalgamados a ele, como sujeito autônomo, consciente e criador.

Para Freire (1999, p. 43) "[...] a prática docente crítica, implicante do pensar certo, envolve o movimento dinâmico, dialético, entre o fazer e o pensar sobre o fazer". Nesse sentido, a prática docente acrítica produz um saber ingênuo, que precisa ser investigado criticamente, com rigorosidade e curiosidade. É refletindo sobre a prática como algo significativo e inerente ao próprio trabalho que o professor poderá dialogar com sua prática e fazer esse exercício com outros professores.

"A profissão docente é vista hoje como uma prática que conduz à criação idiossincrásica de um conhecimento específico, tácito, não sistemático e ligado à ação" (Schön, 2000, p. 65). Essa nova perspectiva, por um lado, serve para destacar a importância do estudo do pensamento do professor. Por outro lado, faz ver que a formação docente não se dá apenas pela acumulação de cursos, conteúdos e técnicas, mas sim, através de um trabalho permanente de "reflexividade" crítica e de construção de uma identidade pessoal-profissional (Santos, 2011).

A valorização da perspectiva crítico-reflexiva reside no conhecimento da docência como forma de investigação e de experimentação. Ao refletir sobre a própria ação, o docente constrói uma teoria original, explicativa da sua prática, contribuindo para a sistematização de novos conhecimentos e, o que é igualmente importante, estimulando a autonomia intelectual e consolidando a crença na sua possibilidade de profissional capaz de pensar e promover mudanças (Zeichner, 2000).

Nesse contexto, a epistemologia da prática implica no reconhecimento de um saber oriundo, mobilizado e reconstruído nas práticas docentes. Busca compreender e elucidar a produção de saberes no bojo da experiência docente - saberes subjetivos que se objetivam na ação. 
Nesse contexto o educador é visto como um profissional do saber: domina determinados saberes, que, em situação de ensino, transforma dando novas configurações a estes e, ao mesmo tempo, assegurando a dimensão ética de sua práxis cotidiana. Ao mesmo tempo, a intersubjetividade da ecologia da classe. [...]. Concebemos que esses saberes constituem um repertório que o docente não somente domina como transforma, produzindo os significados e as configurações destes na sua práxis cotidiana (Therrien, 2006, p. 70).

A noção de saber assumida engloba, num sentido amplo, os conhecimentos, as competências, as habilidades e as atitudes ou o que convencionamos chamar de saber, saber-fazer e saber-ser.

A compreensão de que os saberes pedagógicos persistem a prática docente dos professores abre possibilidades de crítica e incentiva a construção de novos paradigmas para o ensino. Com base nisso, pode-se entender o lugar especial que os professores assumem no processo de ensino e aprendizagem. [...] A atividade docente é uma prática social complexa que combina atitudes, experiências, visões de mundo, habilidades e conhecimentos condicionados pelas diferentes histórias de vida dos professores (D’Ávila; Sonneville, 2008, p. 33-34).

Esse pressuposto nos conduz a considerar os professores como intelectuais (Giroux, 1997) e sujeitos culturais que, no contexto real de prática, produzem saberes e se orientam adotando também outros referenciais não necessariamente universitários: saberes práticos de ação que se consolidam como saberes de experiência. Sacristán (1996, p. 17) assinala que "[...] dizer que um professor se nutre de raízes culturais e não da ciência nos obriga a considerar os ambientes de aprendizagem, os contextos nos quais elas surgem e as condições de trabalho em que vai trabalhar".

Nesse sentido, a prática social abre a possibilidade para que os sujeitos no trabalho confrontem as situações conflitantes, podendo nelas intervir, de acordo com o seu grau de conscientização. "A concepção de trabalho como fonte de conhecimento implica em compreendê-lo como atividade teórico-prática que se traduz em um processo constante de ação-reflexão e, novamente ação transformadora" (Vasquez, 1977, p. 284).

Tardif (2002, p. 255) conceitua epistemologia da prática profissional como o "[...] estudo do conjunto dos saberes utilizados realmente pelos profissionais em seu espaço de trabatho cotidiano para desempenhar todas as suas tarefas". Por saberes, o autor os compreende, no sentido lato, como hábitos, atitudes, conhecimentos, competências, habilidades; em outras palavras, aquilo que muitas vezes foi chamado de saber, saber-ser e saber-fazer. Sua definição propõe a epistemologia da prática profissional como pesquisa, cuja ideia é a de formular um objeto de estudo peculiar à prática dos professores: os saberes docentes. Nesse sentido, a epistemologia da prática pode ser entendida tanto como um campo teórico-metodológico que procura explicar o modelo em que se situam a práticas, como os saberes e os sentidos por ele produzidos, ou seja, a racionalidade em que está apoiado. Nesse caso, o profissional é um sujeito epistêmico. 
De modo geral, essa epistemologia assume a tese de que a prática profissional constitui um lugar autônomo e singular de formação, bem como um espaço fecundo de produção de saberes originados a partir da atividade profissional crítico-reflexiva do docente (Tardif, 2002).

Por sua vez, Schön (2000, p. 25) propõe uma epistemologia da prática, que surge do conhecimento que os professores constroem a partir da reflexão na prática e sobre suas práticas, "pensar o que fazem, enquanto fazem", em situações de incerteza, singularidade e conflito. Ele ao desenvolver o ensino prático reflexivo, esclarece que é "[...] um ensino prático voltado para ajudar os estudantes a adquirirem os tipos de talento artísticos essenciais para atuarem em zonas indeterminadas da prática". São características do ensino prático-reflexivo: o aprender fazendo, a instrução e o diálogo de reflexão-na-ação entre professor e estudante.

A epistemologia da prática profissional tem a intenção de revelar e compreender como os saberes profissionais são concretizados nas tarefas dos professores, e como e por que esses os incorporam, produzem, utilizam, aplicam, validam, transformam, ressignificam ou abandonam, em função dos limites, das contingências e dos recursos inerentes às atividades educativas.

A ação educativa não é uma atividade qualquer, um fazer por "fazer", mas um ato intencional, como pertinentemente ressalva a Teoria da Ação Comunicativa, de Habermas (1997). Ela manifesta a intencionalidade do coletivo de sujeitos. A intencionalidade coletiva, porém, é impossível ser reconstituída sem que os envolvidos explicitem as razões que motivam suas práticas, pois é produzida pela ação reflexiva, crítica e situada. Para tanto, é preciso, como adverte Peres (2000, p. 225), "[...] compreender o como e o porquê dos comportamentos docentes numa perspectiva contextualizada".

Para Pérez Gómez (1992), a capacidade reflexiva configura-se como componente fundamental da compreensão da racionalidade que norteia o pensamento e a ação do professor. É a capacidade reflexiva do docente que the possibilita enfrentar as situações complexas, urgentes e divergentes da prática. É ela que garante intervenção prática racional.

Com respeito à natureza da racionalidade, diz Boufleuer (2001, p. 23):

[...] o critério de racionalidade está na forma como os sujeitos fazem uso do saber encarnado em suas ações e manifestações simbólicas, podemos chamar de racional o sujeito que é capaz de fundamentar a conviç̧ão que motiva sua ação ou sua fala e que, em princípio, sempre é susceptível de crítica.

As formulações de Therrien e Sousa (2000, p. 4), também contribuem para a compreensão do caráter ético da racionalidade prática do professor, ao destacar que "[...] as direções dadas ao processo de ensino-aprendizagem pelo docente situam-se num patamar ético porque envolve decisões de caráter político-ideológico suscetíveis de afetar a concepção de vida e mundo do aluno aprendiz". Esses aspectos destacam a dimensão ético-reflexiva do trabalho docente, bem como a natureza da cultura do professor.

No cotidiano da ação docente, o professor desenvolve a racionalidade prática do trabalho, que se manifesta na recorrência a critérios de julgamento para balizar sua intervenção em dada situação. A racionalidade prática, ao dar conteúdo e forma à ação docente, o que é compartilhado e legitimado pelo coletivo, vai configurando a cultura do grupo. A cultura do- 
cente é constituída da pluralidade de saberes ou da base de conhecimentos constantemente mobilizada pelo professor, no desenvolvimento da ação pedagógica na sala de aula (Therrien e Sousa, 2000); saberes diretamente imbricados com as teorias e crenças dos professores sobre seu trabalho em constante interação.

Sobre o caráter interativo do trabalho do professor, Therrien e Sousa (2000, p. 115) acrescentam que pressupõe:

[...] que o docente domine uma base essencial de saberes que ele articula no contexto da ação, os quais the fornecem competência para a gestão pedagógica da sala de aula. Completada pelas teorias da argumentação essa abordagem permite caracterizar a racionalidade prática do educador e desvelar elementos definidores de sua identidade.

Essa perspectiva aponta a racionalidade prática da docência como elemento primordial no estabelecimento da cultura profissional do professor, em determinado contexto de ação, espaço de socialização, configuração e reconfiguração de identidade, cujas especificidades podem ser assim identificadas: atividade que requer saberes específicos à práxis profissional; ação que solicita a superação da dimensão técnica de aplicação direta, posicionando-se de forma dialética; um profissional responsável pelo processo de formação humana, que atua orientado por fins éticos (Therrien; Sousa, 2000).

A racionalidade prática do professor se apresenta como elemento constitutivo de sua cultura, reconhecendo-o como profissional com identidade própria e produtor de saberes situados e contextualizados. A explicitação das razões que fundamentam as decisões dos docentes, no seu local de trabalho, com arrimo nas atividades curriculares, na organização do tempo e do espaço, nas múltiplas interações que se estabelecem nesse espaço, é fundamental à compreensão da cultura dos profissionais.

Consoante Carvalho (2007), nesse contexto, apresenta-se a "gestão da matéria" e a "gestão de sala de aula" que são construções mentais para caracterizar um conjunto de ações solicitadas pelo trabalho docente que efetivam no decorrer da prática educativa. Como a prática educativa está dimensionada pela matéria e as inter-relações dos sujeitos na ecologia da sala de aula para significá-la, esses dois eixos caracterizam as funções pedagógicas do trabalho docente.

A gestão da matéria faz da prática educativa um processo eminentemente criativo, de aprendizagem mútua e relativamente autônoma à proporção que os conteúdos de ensino são prescritos, para Therrien e Loiola (2001). Entretanto, ainda que estes sejam prescritos, de alguma forma, o professor precisa decidir o que fazer com eles. Carvalho (2007) destaca que o planejamento da gestão da matéria requer também reflexões acerca da organização da classe.

A gestão da classe é caracterizada pela natureza humana do trabalho docente e abarca sua dimensão axiológica. Requer a busca de formas de colaboração entre alunos e professor, de motivação, de disciplina e de ética, sem as quais fica impossível realizar o ensino.

Gauthier et al. (1998, p. 23) definem a gestão de classe como um "[...] conjunto de operações que o professor aciona para manter certo tipo de ordem e agir de maneira a fazer a aprendizagem ser absorvida pelo grupo". A gestão de classe é o momento em que a 
matéria vai ser colocada em prática e implica em decisões conjuntas. Os autores também afirmam que a gestão de classe é a variável que determina mais fortemente a aprendizagem dos alunos.

professor necessariamente compartilhará com o aluno suas intenções, ao tempo em que poderão deliberar juntos os rumos da ação educativa. Provavelmente seja o aspecto mais conflituoso do trabalho docente, devido à heterogeneidade de uma sala de aula e a simultaneidade com que os fatos ocorrem nesse âmbito. Tais fatos exigem do professor demandas imediatas, em razão de os antagonismos existentes entre o que é proposto pelo professor e as respostas do grupo de alunos.

Admitindo-se sua essência interativa e a eminência cooperativa, o ideal mesmo é que ocorra nos moldes da ação comunicativa, como propõe Boufleuer (2001). Caso contrário, se o professor não tiver a intenção de buscar um entendimento entre os alunos não surte o efeito desejado.

A gestão de classe requer deliberações constantes que solicitam ao professor competências que auxiliam e desenvolvem sua capacidade de decidir bem sobre determinada situação na ecologia de sala de aula. As deliberações têm como fundamento o juízo prático do professor, sua epistemologia da prática. Baseiam-se em um pensamento reflexivo, que aqui chamamos de racionalidade pedagógica, e são tomadas em função do alcance de finalidades. Esta racionalidade desempenha uma função básica, porque, ao escolher os meios que fará uso, o professor também deverá decidir sobre os fins éticos.

Tanto na gestão da matéria como na gestão da sala de aula, o professor como mediador pedagógico detém autonomia para transformação pedagógica da matéria, sendo a autonomia determinada por exigências de responsabilidade, competência e controle na satisfação dos objetivos perseguidos. Ainda que essa autonomia seja relativa à proporção que as tarefas do ensino são prescritas como asseveram categoricamente Therrien e Loiola (2001), a competência constitui o elemento central da dimensão da autonomia do professor.

\section{A docência no ensino superior na visão dos sujeitos de pesquisa... com- passos e descompassos...}

Um dos elementos ressaltados no conjunto dos dados obtidos, recorte de análise para este artigo, diz respeito às apreciações que os sujeitos da pesquisa atribuem à prática pedagógica em situação de ensino e as mudanças nela operadas no ensino superior. Essas apreciações foram organizadas em quatro categorias temáticas não excludentes: (a) intervenção em sala de aula e as mudanças na prática pedagógica, (b) os conhecimentos teóricos e práticos adquiridos ao longo do processo formativo, (c) o convívio profissional e pessoal e (d) o saber-fazer em situação de ensino.

A primeira apreciação que os sujeitos atribuem à prática pedagógica em situação de ensino e as mudanças nela operadas se referem à intervenção em sala de aula e as mudanças na prática pedagógica, onde os professores relembraram as situações de ensino vivenciadas que exigiram rotinas pedagógicas interativas e dinâmicas. Destacaram ainda, a inserção de novas atividades contextualizadas e que possibilitasse uma efetiva partici- 
pação dos alunos na construção dos saberes, além da continuidade da rotina pedagógica efetivada na prática da elaboração do planejamento das atividades a serem vivenciadas na sala de aula.

Então, quando eu comecei, eu tinha uma visão mais restrita assim de sala de aula, mas à medida que eu fui trabalhando com outros profissionais, eu fui vendo outras formas de trabalhar com os grupos, formas mais interativas, mais dinâmicas, que possibilitasse mais a participação das pessoas (G8).

Pra mim, existe mudança. Ensinar sempre esteve presente na minha vida, mas o que mudou... eu estou pensando mais na minha prática, na minha relação com os alunos, mas confesso que sinto a falta do domínio para planejar minhas aulas. As atividades de pesquisa na Iniciação Científica contribuíram um pouco para inserção de novas atividades, mas não teve tanto impacto (G5).

A partir desses depoimentos, podemos perceber também que a mudança na prática pedagógica surgiu por meio do convívio com outros professores mais experientes, o que possibilitou o (G8) intervir em sala de aula através de outras formas de trabalhar, trazendo para o seu cotidiano escolar atividades interativas e dinâmicas que permitissem a participação de todo o grupo.

A experiência em atividades de pesquisa durante a Iniciação Científica fez com que (G5) inserisse novas atividades em sala de aula, relacionadas ao tema trabalhado em sua investigação. Essa experiência possibilitou perceber outras maneiras de trabalhar em sala de aula com os alunos, revendo as práticas utilizadas anteriormente. Portanto, o papel da pesquisa na formação do professor foi fundamental para que ele percebesse as possibilidades do ensino pela pesquisa, visando uma efetiva aprendizagem dos alunos.

Nessa perspectiva e direção, o planejamento das ações é concebido como uma das exigências do trabalho docente, ou seja, é no momento de ação-reflexão-ação de sua prática que o professor mobiliza diferentes saberes. Segundo Freire (1999), o professor na realização do seu trabalho docente precisa dominar o conteúdo, apresentar intencionalidade, escolha e execução de metodologia adequada que possibilite a mediação de saberes e a construção de aprendizagens significativas.

Diante dessa atitude reflexiva os professores evidenciam os aspectos que foram sendo modificados na sua prática pedagógica. Planejar, no entanto, não significa garantir que as ocorrências pedagógicas na sala de aula serão todas controladas e previsíveis. Ao contrário, muitos estudos (Gauthier et al., 1998; Tardif, 2002; Zeichner, 2000; Zabalza, 2000, 2004) têm apontado que a prática pedagógica é permeada por uma certa imprevisibilidade e pelo caráter interativo. De modo que, mesmo contendo um conjunto de regularidades, o trabalho docente se desenvolve de forma dinâmica, cedendo lugar com frequência, para as "urgências" ou "soluções rápidas", que muitas vezes não foram definidas a priori no planejamento.

Os conhecimentos teóricos e práticos adquiridos ao longo do processo formativo constituem a segunda categoria de análise e nos remete a uma segunda apreciação. Podemos observar a priori que a mudança operada na prática pedagógica dos sujeitos investigados se deu 
ao longo do exercício profissional através da articulação dos conhecimentos teóricos e com as situações práticas, quando a (G6) percebeu que "não existe receita pronta" para enfrentar as diversas situações pedagógicas que acontecem em sala de aula. Ao contrário, o exercício da docência foi revelando para esse professor a inexistência de receituários, a necessidade de manter uma atitude investigativa, a curiosidade, a busca pela informação para conseguir atuar com autonomia.

Então, assim, mudou. Antes, lógico, temos uma visão do que é ser professor, a questão da receita pronta. Eu vou chegar aqui e vou encontrar uma receita. Eu descobrir que não existe essa receita pronta, e que, na minha sala de aula, existiam situações que aconteciam todos os dias e que variavam e que eu tinha que realmente buscar informação, ter um conhecimento maior, estudar mais para poder. Então, a contribuição foi essa, que eu poderia resolver aquelas situações e que tinha uma forma e que eu encontrei essa forma aqui, não através de receita, mas que eu tinha que buscar (G6).

No conjunto dos dados, identificamos ainda uma terceira apreciação da mudança na prática pedagógica que se refere ao convívio profissional e pessoal. No convívio profissional, o (Gl) reconhece que a presença de professores mais experientes pertencentes ao seu setor de ensino contribuiu para sua identificação com as diversas disciplinas por ele ministrada, sendo importante na constituição dos saberes específicos disciplinares e em situações de prática, bem como de momentos de troca de experiência e reflexividade.

A presença de professores mais experientes pertencentes ao meu setor de ensino contribuiu para minha identificação com as diversas disciplinas por mim ministradas $(\mathrm{Gl})$.

Podemos afirmar que é no convívio profissional com um professor mais experiente que muitas aprendizagens ocorrem, entre elas a aquisição de novos saberes, que servem de referência para atuar nas relações com os alunos e com outros professores. A troca com os pares, consoante Vasconcelos (1998) "[...] possibilita a construção de saberes a partir de situações já vivenciadas por colegas, a partir de situações realizadas". Essas trocas geralmente envolvem experiências dos professores, sejam elas exitosas ou não, tomadas como referencial para as ações docentes posteriores.

Um elemento que nos chamou a atenção nos dados da pesquisa diz respeito ao papel dos cursos de graduação e pós-graduação na "preparação" para docência. Para os sujeitos investigados, constituem espaços de produção e mobilização de saberes específicos da matéria disciplinar, ligados diretamente à produção de conhecimento por intermédio do exercício da pesquisa e pouco se referencia a docência.

○ convívio com professores que trabalhavam na graduação e na pós-graduação foi fundamental para os sujeitos investigados perceberem que através de professores mais experientes é possível ser professor, ficando a exigência para a docência, no depoimento dos sujeitos da pesquisa, restrita ao domínio dos conteúdos específicos da matéria. 
Especificamente no depoimento do (G7), o convívio com os professores trouxe "elementos que foram muito mais importantes" expressando ainda um sentimento de sedução por um componente curricular específico, que o fez perceber a linha de pesquisa que gostaria de atuar como pesquisador e professor.

Para o (G3) esse convívio com professores mais experientes e detentores de grande conhecimento da matéria o incentivou tanto para a pesquisa quanto para o ensino. No entanto para ensinar, consoante o entrevistado, basta saber o conteúdo da disciplina.

Meus professores da graduação e da pós-graduação foram minha inspiração para a pesquisa. Dominavam bem a sua matéria e nos "obrigavam" a pesquisar sobre os conteúdos, por exemplo o de Geomorfologia Geral, hoje ensino essa disciplina e desenvolvo pesquisas nessa área de conhecimento inspirado nele. Ser professor foi por acaso, nem pensava nisso. Apesar de ouvir sempre que para estar onde eu estou hoje precisava fazer pós. Os alunos eram cobrados por isso. Confesso que isso contribui mais para meu papel de pesquisador do que de professor. Ser professor ajuda um pouco nas pesquisas (G7).

Houve durante a pós-graduação determinados professores, determinados autores também, leituras que eu fiz, foram determinantes para o domínio da disciplina. Devido isso, minha prática é muito mais voltada pra pesquisa do que para o ensino. Os elementos que eles traziam, pra mim foram muito mais importantes, eu me senti muito mais seduzido pela pesquisa nessa área, do que propriamente trabalhar no ensino (G3).

Interessante verificar que, além do convívio com os professores, o (G3) realizou leitura de determinados autores que the possibilitou adquirir novos conhecimentos específicos da matéria, como também o conduziu para a pesquisa. É possível perceber a construção do saber específico da matéria no momento em que o professor age investigando, mesmo não intencionalmente, mas que a partir dessa ação passa a incorporar saberes fragmentados que serão utilizados em situações semelhantes, que requerem o mesmo resultado. No entanto, esses saberes não conduzem a uma prática reflexiva crítica na medida em que o curso de pós-graduação não criou um espaço para refletir a pesquisa e o ensino como núcleo fundamente para o desenvolvimento de competências. Isso nos leva a inferir sobre o papel da pós-graduação na formação desse professor - o preparo somente para a pesquisa e não para o ensino.

Outro aspecto a ser destacado se refere ao aprofundamento teórico no processo de formação inicial e na pós-graduação. Dois polos são estabelecidos - a teoria alimentando a pesquisa e os conhecimentos práticos alimentando o ensino. $\bigcirc$ depoimento ilustra:

As contribuições? Contribuição mesmo só para a pesquisa e para aprofundar as teorias no meu campo de investigação. Não fiz licenciatura e minha formação não me preparou para o ensino. Fiz-me professor na prática. Não conhecia ninguém que fosse da área, que fosse professor. Então os conhecimentos para ser professor foram de fato construídos na prática, olhando, observando como agiam meus professores (G10). 
Podemos perceber a partir do depoimento de (G10) que os cursos de graduação e pós-graduação tiveram papel importante na constituição dos saberes específicos para sua prática docente. Os conhecimentos teóricos mobilizados durante o curso de formação inicial e de pós são bastante valorizados pelos sujeitos e visam atender às demandas específicas para pesquisa e não para o ensino.

Existe nesse cenário uma forte influência da racionalidade técnica no discurso dos professores e em sua prática. Para Medeiros e Cabral (2006):

[...] a racionalidade técnica, cujas raízes foram afincadas no positivismo, trouxe historicamente limites para o desenvolvimento profissional do professor e, consequentemente, para o desenvolvimento de uma sociedade que busca por mudanças no contexto social, político e cultural, visto que, naquele modelo, os princípios básicos eram arregimentados por conteúdos formais, cristalizados em grades curriculares, não valorizando, dessa forma, a criatividade e a inovação do professor. Eis o que chamamos de "ranço" da racionalidade técnica (Medeiros; Cabral, 2006, p. 7).

Quanto às mudanças ocorridas a partir da própria experiência pessoal se expressam no depoimento de (G4) que destacou a dinâmica das experiências cotidianas "porque não fazemos a mesma coisa sempre" e a natureza plural e diversa das vivências humanas "sempre há uma mudança, nem é a mesma pessoa, a gente está mudando a cada dia" como fundamentais nesse processo formativo.

Uma quarta aproximação diz respeito ao saber-fazer em situação de ensino operado pelos sujeitos investigados. Nesta categoria nos aproximamos do planejamento de ensino e do saber-ensinar dos docentes.

Na realidade pesquisada, o planejamento é baseado no conteúdo, sem a relação entre os componentes do processo de ensino, a unidade objetivos-conteúdos e métodos, logo sem compreender o valor didático desse planejamento e sem relacioná-lo com o contexto.

De posse das informações levantadas acerca do planejamento das aulas dos docentes investigados, procuramos observar sua prática. As aulas foram observadas por um período médio de cinco semanas. Dos cinco professores que autorizaram nossa presença em sala, três se mostraram bastante à vontade e receptivos, dois se sentiam incomodados e chegaram a verbalizar essa percepção. Ao fazerem isso, destacaram sempre questões referentes à não formação pedagógica "Mas você não vai rir de mim", "você não vai nos ensinar a dar aula, vai?".

Iniciamos as observações conscientes das palavras de Zabalza (2000), para o qual a prática obedece a múltiplos determinantes, tem sua justificação em parâmetros institucionais, organizativos, tradições metodológicas, possibilidades reais dos professores, dos meios e condições físicas existentes, mas também é fluida, fugidia, difícil de limitar com coordenadas simples e, além do mais, complexa, já que nela se expressam múltiplos fatores, ideias, valores, hábitos pedagógicos etc. 
Masetto (2003) conceitua sala de aula como o espaço onde e tempo durante o qual os sujeitos de um processo de aprendizagem (professores e alunos) se encontram para juntos realizarem uma série de ações (na verdade "interações") na busca de um desenvolvimento pessoal, profissional e como cidadão.

Um dado significativo é que nas aulas de quatro professores observados havia a preocupação em criar um ambiente positivo e propício à aprendizagem, e também de incentivar a participação dos alunos no processo de ensino-aprendizagem.

Em apenas uma das aulas observadas, o professor não demonstrava a preocupação de buscar a participação dos alunos. Expunha a matéria e em seguida resolvia os exercícios. Às vezes fazia perguntas à sala, mas ele mesmo dava as respostas. A aula era um monólogo. $\bigcirc$ intuito era desenvolver o conteúdo sem que houvesse possibilidade de imprevistos, entre eles, dúvidas de alunos. As palavras de Vasconcelos (1998, p. 25) parecem se referir a práticas como essa:

A situação de alienação se caracteriza pela falta de compreensão e domínio nos vários aspectos da tarefa educativa. Assim, percebemos que ao educador falta clareza com relação à realidade em que ele vive, não dominando, por exemplo, como os fatos e fenômenos chegaram ao ponto em que estão hoje (dimensão sociológica, histórico-processual); falta clareza quanto à finalidade daquilo que ele faz: educação para quê, a favor de quem, contra quem, que tipo de homem e de sociedade formar etc. (dimensão política, filosófica), e, finalmente, falta clareza a sua ação mais específica em sala de aula (dimensão pedagógica).

A preocupação em desenvolver o pensamento crítico dos alunos, só foi percebida na prática de dois professores. Estes relacionavam o conteúdo explicado com a realidade socioeconômica e com questões do meio ambiente, ao mesmo tempo buscavam aplicar questões teóricas à prática da profissão.

Em relação à sequencialização das aulas, duas realidades se mostraram. Uma, nas aulas de três professores, em que não havia nenhum planejamento que propiciasse ao aluno a construção de uma linha de pensamento, a partir de aulas sistematizadas. Outra, nas aulas de dois professores, em que havia a preocupação de um encadeamento lógico, inclusive com a retomada de tópicos anteriormente trabalhados. E ainda a de indicar leituras para a próxima aula, objetivando o enriquecimento do debate.

Percebemos, explicitamente, nas práticas observadas a necessidade de formação pedagógica para os professores universitários não como fim, mas como meio de possibilidades de estreitamento do hiato teoria prática, tendo o ensino como mecanismo para uma prática situada. Apesar de os sujeitos pesquisados não terem verbalizado essa necessidade nas entrevistas, o conjunto dos dados colhidos e o resultado das análises, nos leva afirmar que os professores têm dificuldades em construir saberes pedagógico-docentes, na relação com os saberes específicos de sua área e na relação com os saberes da sua própria experiência docente, dificultando o processo de transformação da matéria em algo ensinável, compreensível e que gere aprendizagens. 


\section{Algumas conclusões para continuidade do debate}

Neste artigo, analisamos os saberes docentes no âmbito do trabalho dos professores como profissionais reflexivo-críticos, para identificar as racionalidades que movem a ação docente no ensino superior em situação de trabalho, especificamente, de docentes sem formação pedagógica.

A tese central deste estudo é que os professores sem formação específica para a docência mobilizam saberes na prática - saberes empíricos oriundos de suas inter-relações. No entanto, esses saberes não dão conta das incertezas em situação de trabalho e, isolados de um contexto, não superam a falta de uma formação pedagógica.

O estudo partiu da ideia de que a preparação didático-pedagógica é necessária para a formação docente. Foi a análise das representações dos professores sobre seu trabalho que nos permitiu, em primeiro lugar, conhecer os sentidos e os significados que eles atribuem aos saberes docentes. Além disso, trouxe elementos para compreender como os bacharéis-geógrafos sem formação docente desenvolvem sua prática pedagógica.

Grande parte das representações que os professores de nossa pesquisa têm sobre sua atividade profissional decorre de uma cultura gestada no processo de construção do ensino superior brasileiro, cuja trajetória sempre esteve voltada à formação profissional. Assim, o domínio do conteúdo específico da disciplina tem forte influência na atividade do bacharel, sendo este o saber que orienta sua prática.

Investigar a prática docente de professores não é tão simples, pois envolve todo um tecido complexo que foi tecido nos moldes da racionalidade técnica, sobretudo quando os sujeitos observados são professores universitários.

O estado defensivo com que os sujeitos se comportavam diante de nossa presença em seu espaço de trabalho era claro. Mesmo não inseguros do conteúdo da matéria, tendo pleno domínio do conteúdo de sua disciplina, se sentiam incomodados pela falta do conhecimento pedagógico, entretanto esse fato não os impedia de continuar a "dar sua aula". "Imitar" seus antigos mestres constituía-se o mecanismo determinante e "suficiente" para transmitir e reproduzir o conteúdo disciplinar.

Os achados dessa investigação nos permitiram concluir que: (a) o professor-bacharel dos cursos investigados tem uma pedagogia própria pautada na transmissão do conteúdo, (b) o pedagógico é visto como transferência de conteúdo, (c) segundo suas representações, os professores não consideram a formação pedagógica como base para a docência, mas sim os saberes da área específica da sua formação profissional. Portanto, torna-se necessário superar a crença de que para ser bom professor basta conhecer profundamente e conseguir transmitir com clareza determinado conteúdo, ou até mesmo como no caso da educação superior, ser um bom pesquisador.

Esses achados nos põem desafios de investigar modos de trabalhar a formação e a prática do docente de educação superior que permita produzir e mobilizar saberes situados na docência. $\bigcirc$ tornar-se professor é uma atividade de aprendizagem e, para isso, são requeridas capacidades e habilidades específicas para a profissão docente. 


\section{Referências}

BARDIN, L. Análise do conteúdo. Trad. Luís Antero Reto e Augusto Pinheiro. Lisboa: Edições 70, 1995.

BEHRENS, M. A. A formação pedagógica e os desafios do mundo moderno. In: MASETTO, M. T. (Org.). Docência na universidade. Campinas: Papirus, 2003. p. 57-68.

BOUFLEUER, J. P. Pedagogia da ação comunicativa: uma leitura de Habermas. 3. ed. Ijuí, RS: Unijuí, 2001.

CARVALHO, A. D. F. A racionalidade pedagógica da ação dos formadores de professores: um estudo sobre a epistemologia da prática docente nos cursos de licenciatura da Universidade Federal do Piauí. Tese (Doutorado em Educação) - Universidade Federal do Ceará, Fortaleza, 2007.

COULON, A. Etnometodologia. Trad. Epharim Ferreira Alves. Petrópolis, RJ: Vozes, 1995.

D'ÁVILA, M. C.; SONNEVILLE, J. Trilhas percorridas na formação de professores: da epistemologia da prática à fenomenologia existencial. In: D’ÁVILA, M. C.; VEIGA, I. P. A. (Org.). Profissão docente: novos sentidos, novas perspectivas. Campinas, SP: Papirus, 2008. p. 23-44.

DIAS, A. M. I. Leitura e (auto)formação: caminhos percorridos por docentes na educação superior. In: VEIGA, I. P. A.; VIANA, C. M. A. Q. Docentes para a educação superior: processos formativos. Campinas, SP: Papirus, 2010. p. 71-100.

FREIRE, P. Pedagogia da autonomia. São Paulo: Paz e Terra, 1999.

GAUTHIER, C. et al. Por uma teoria da pedagogia: pesquisas contemporâneas sobre o saber docente. ljuí, RS: Unijuí, 1998. (Coleção Fronteiras da Educação).

GIROUX, H. A. Os professores como intelectuais. Porto Alegre: Artmed, 1997.

HABERMAS, J. Teoría de la acción comunicativa: complementos y estudios previos. Madrid: Cátedra, 1997.

MASETTO, M. T. Docência na universidade. Campinas: Papirus, 2003.

. (Org.). Competência pedagógica do professor universitário. São Paulo: Summus, 2002.

MEDEIROS, M. V.; CABRAL, C. L. O. Formação docente: da teoria à prática em uma abordagem sócio-histórica. Revista Científica e-Curriculum, São Paulo, v. 1, n. 2, jun. 2006.

MINAYO, M. C. S. (Org.). Pesquisa Social: teoria, método e criatividade. Petrópolis, RJ: Vozes, 1994.

MOREIRA, A. F.; LOPES, A. C.; MACEDO, E. Socialização profissional de professores: as instituições formadoras: relatório de pesquisa. Rio de Janeiro: UFRJ, 1998.

PERES, A. N. Educação intercultural: utopia ou realidade? Porto-PT: Profedições, 2000. 
PÉREZ GÓMEZ, A. O pensamento prático do professor: a formação do professor como profissional reflexivo. In: NÓVOA, A. (Org.). Os professores e sua formação. Lisboa: Dom Quixote, 1992. p. 93-114.

PIMENTA, S. G. Professor reflexivo: construindo uma crítica. In: PIMENTA, S. G.; GHEDIN, L. E. (Org.). Professor reflexivo no Brasil: gênese e crítica de um conceito. 4. ed. São Paulo: Cortez, 2006. p. 17-52.

PIMENTA, S. G.; ANASTASIOU, L. G. C. Docência no ensino superior. São Paulo: Cortez, 2002.

SACRISTÁN, J. G. Poderes instáveis em educação. Porto Alegre: Artmed Sul, 1999.

. Tendências investigativas na formação de professores. Transcrição e tradução de José Carlos Libâneo. In: REUNIÃO ANUAL ANPED, 19., 1996, Caxambu, Atas... Caxambu: Anped, 1996. p. 12-27.

SANTOS, F. K. S. O trabalho e a mobilização de saberes docentes: limites e possibilidades da racionalidade pedagógica na educação superior. Tese (Doutorado em Educação) - Faculdade de Educação, Universidade Federal do Ceará, Fortaleza-CE, 2011.

SCHÖN, D. A. Educando o profissional reflexivo: um novo design para o ensino e a aprendizagem. Porto Alegre: Artmed, 2000.

TARDIF, M. Saberes docentes e formação de professores. São Paulo: Vozes, 2002. Saberes profissionais dos professores e conhecimentos universitários: elementos para uma epistemologia da prática profissional dos professores e suas consequências em relação à formação para o magistério. Revista Brasileira de Educação, São Paulo: Anped, n. 13, p. 5-24, jan./abr. 1999.

TARDIF, M.; LESSARD, C.; LAHAYE, L. Os professores face ao saber: esboço de uma problemática do saber docente. Teoria e Educação, Porto Alegre, n. 4, p. 215-233, 1991.

THERRIEN, J.; LOIOLA, F. A. Experiência e competência no ensino: pistas de reflexões sobre a natureza do saber-ensinar na perspectiva da ergonomia do trabalho docente. Educação \& Sociedade, v. XXII, n. 74, abr. 2001.

THERRIEN, J.; SOUSA, A. Cultura docente e gestão pedagógica: a racionalidade prática dos saberes do saber-fazer racionalidade do agir docente - elementos para uma análise da formação prática. In: NOBRE, M. D.; THERRIEN, J. (Org.). Artesãos de um outro oficio: múltiplos saberes e práticas no cotidiano escolar. São Paulo: Annablume, 2000. p. 111-126.

THERRIEN, J. Os saberes da racionalidade pedagógica na sociedade contemporânea. Revista Educativa, Goiânia, v. 9, n. 1, p. 67-81, 2006.

Saber de experiência, identidade e competência profissional: como os docentes produzem sua profissão. Contexto $\mathcal{E}$ Educação, ljuí-RS, v. 12, n. 48, p. 7-36, 1997. 
Trabalho e saber: a interação no contexto da pós-modernidade. In: MARKERT, W. (Org.). Trabalho, qualificação e politecnia. Campinas, SP: Papirus, 1996. p. 53-70.

VASCONCELOS, M. L. M. C. Contribuindo para a formação de professores universitários: relatos de experiência. In: MASETTO, M. (Org.). Docência na universidade. Campinas, SP: Papirus, 1998. p. 77-94.

VASQUEZ, A. S. Filosofia da práxis. 2. ed. Rio de Janeiro: Paz e Terra, 1977.

ZABALZA, M. O ensino universitário: seu cenário e seus protagonistas. Trad. Ernani Rosa. Porto Alegre: Artmed, 2004.

. El papel de los departamentos en la mejora de la calidad de la docencia universitaria. Revista Interuniversitaria de Formación del Profesorado, Zaragoza, v. 38, n. 4, p. 45-68, 2000.

ZEICHNER, K. Formação de professores: contato direto com a realidade da escola. In: Presença pedagógica, Belo Horizonte, v. 6, n. 34, jul./ago, p. 5-15, 2000. 